\title{
ECOS DERRIDEANOS LEYENDO EL ULISES DE JOYCE
}

\section{Luis FERRERO CARRACEDO}

I. E. S. Cervantes (Madrid)

\section{Entre Husserl y Joyce}

$\mathrm{T}$ Tan solo unos ecos: ecos derrideanos -de Glas, de Circonfession, de Parages...leyendo el Ulises de Joyce. Ecos tardíos, tal vez no pensados. ¿Sobrevenidos, más bien? Quizá ecos no sea la palabra exacta. Tal vez se trate de otra cosa difícil de capturar: ¿resonancias, intersecciones...? Sabemos de la afinidad profunda y a la vez compleja, presente ya desde el principio, sólo en diversos momentos sacada a la luz -momentos brillantes y seductores-, del pensamiento de Derrida con la obra literaria de Joyce. Ya en 1956, durante su estancia como «oyente especial» en la Universidad de Harvard «con el pretexto un poco ficticio de consultar allí los microfilmes de los inéditos de Husserl» (Bennington, 1991: 303), pasó Derrida gran parte de su tiempo leyendo a Joyce en la Widener Library. Husserl y Joyce serán desde entonces como dos columnas, dos caminos, que se intersecan, se traslapan, en una obra que trabaja el lenguaje como el demiurgo platónico trabaja la chóra. En su «Introducción» a El origen de la Geometría de Husserl (Derrida, 1962) tenemos ya un hito, una marca que señala de forma certera el camino -si podemos hablar de camino- derrideano al apuntar con clarividencia la duplicidad, la tensión y a la vez la interdependencia entre los proyectos de Joyce y de Husserl: frente a la equivocidad de la empiria y la cultura, a las resonancias y asociaciones pasivas, a lo intraducible de una Babel de lenguas, que Joyce ofrece en Ulysses y en Finnegans Wake, el proyecto husserliano intenta reducir, empobreciéndolo sin duda como una necesidad inevitable, el lenguaje fáctico y empírico a su núcleo o corazón traducible para recoger, re-cordar, la estructura pura de la historia, el reino de la univocidad. Esa duplicidad e interdependencia, esa relación en zigzag entre dos estrategias, dos grandes modelos de pensamiento, vuelve de nuevo a 
latir en 1982 con ocasión de un coloquio en torno a Joyce ${ }^{1}$, al dejar en sus palabras testimonio de una relación «singular», «activa» e «invasora» (Derrida, 1987: 24) con una obra que admira, la de Joyce, cuya lectura siente como una experiencia bordeante (Derrida, 1987: 24: «la zambullida incesante me vuelve a lanzar a la orilla, en el borde de otra inmersión posible, al infinito»), a la vez que la contrapone al paradigma husserliano, el paradigma de las «cosas de la academia», cuya escritura siente acompañada por un «fantasma de Joyce siempre al abordaje» (Derrida, 1987: 27), hasta el punto de presentar La farmacia de Platón como «una suerte de lectura indirecta, distraída quizás, de Finnegans Wake» (Derrida, 1987: 29), o de calificar Glas, esa «larga procesión, en dos columnas», como «una suerte de Wake» (Derrida, 1987: 28), o de confesar que La Carte Postale «está frecuentada por Joyce, cuya estela funeraria se levanta en el centro de Envíos (visita del cementerio de Zurich)» (Derrida, 1987: 28). Así se lo confirmaba a Derek Atridge en una entrevista que tuvo lugar en Laguna Beach en abril de 1989:

Ulises llega como una novela entre otras que usted coloca en su estantería e inscribe en una genealogía. Tiene sus ascendientes y sus descendientes. Pero Joyce sueña con una institución especial para su obra, inaugurada por algo así como un nuevo orden. ¿Y acaso no lo ha alcanzado hasta cierto punto? Cuando he hablado acerca de él, como hice en "Ulysse Gramophone", tuve realmente que entender y también compartir su sueño; no sólo compartirlo haciéndolo mío, reconociendo el mío en él, sino también compartirlo perteneciendo al sueño de Joyce, tomando parte en él, rondando alrededor de su espacio. ¿Acaso no estamos, hoy, gentes y caracteres, constituidos en parte (como lectores, escritores, críticos, profesores) en el sueño de Joyce y a través de él? ¿Acaso no somos el sueño de Joyce, sus lectores soñados, aquellos con los que él soñaba y el que nosotros soñamos ser a su vez? (Derrida, 1992: 74).

Joyce como sueño, Joyce como espectro, merodeando en la «ecocámara de intertextualidad», en el «archivo-universo de textualidad» (Boheemen-Saaf, 2004: 178) que constituye la gran obra que Derrida ha construido girando en torno a eso que podemos llamar «texto» ${ }^{2}$. Hasta aquí podríamos decir que Derrida siguió la consigna kantiana: «De nobis ipsis silemus». Pero será sobre todo en Circonfession, y a partir de esta confesión sui generis en diversos coloquios y entrevistas, donde Derrida, meditando sobre su propia identidad y herencia judía, como acertadamente ha apuntado

\footnotetext{
${ }^{1}$ En el Coloquio Pour James Joyce, organizado por el Centro Georges Pompidou en colaboración con la Embajada de Irlanda en París y el British Council, Derrida pronunció el 12 de noviembre de 1982 un discurso improvisado a partir de algunas notas -cuya trascripción, con el título Deux mots pour Joyce, fue publicada primeramente en inglés (Derrida, 1984: 145-160) y posteriormente en francés (Derrida, 1985 y 1987)- en el cual resume su relación entreverada con Husserl y con Joyce. Sobre esta mutua relación y relatividad del proyecto joyciano y el husserlinao en Derrida, remito a J. D. Caputo (1997: 182-184) y a L. Lawlord (2002: 122 ss.). En un trabajo anterior Lawlord hacía hincapié en la idea que «el proyecto de Joyce depende del de Husserl, ya que no habría recolección de empiricidad sin una estructura que soporte la trasmisión; el de Husserl depende del de Joyce ya que no podría recordar la estructura de la historia si no se tuviera en cuenta la génesis» (Lawlord, 1995: 163, n. 35).

${ }^{2}$ Ya en 1989 destacaba Cristina de Peretti la importancia de la noción de "texto" en la obra de Derrida (véase Peretti, 1989)
} 
Alan Roughley (1999: 18), nos dejará huellas de profundas resonancias con Ulises, que trascienden el campo del lenguaje y de la historia, desvelando zonas o experiencias más comprometidas con la propia circunstancia del pensador, del escritor, como son la relación con la religión, con la muerte, con la tierra, con la madre. Será sobre este campo sobre el que dejaremos resonar sus ecos.

\section{Entre restos: Dios, la mar, la madre}

Leyendo el Ulises, después de Glas, después de Circonfession... «Tú no quisiste arrodillarte a rezar por tu madre en la agonía cuando ella te lo pidió -le reprochó Buck Mulligan a Stephen Dedalus-. ¿Por qué? Porque llevas dentro esa maldita vena jesuítica, sólo que inyectada al revés» (Joyce, 1922: 9; 1976: I, 78). Citas litúrgicas, cuestiones quodlibetales, alusiones tomistas, dogmas teológicos, preguntas a modo de catecismo... Podemos pensar que el Ulises es, entre otras muchas cosas, un ejercicio de deconstrucción del cristianismo. Y como tal ejercicio de deconstrucción, implementa, como condición de posibilidad y a la vez como producto efectivo, una teoría de los restos. El cristianismo -y más en concreto el catolicismo- como resto: lo desechado pero de lo que no podemos prescindir. Lo odiado, o rechazado, pero a la vez lo íntimamente portado como una adherencia inseparable. El Ulises es un tratado de teología. Un tratado como ejercicio de deconstrucción; una teología de los restos. Una leimatoteología. Dios como resto. El resto desechable que siempre nos acompaña. El resto adherido del que nos queremos desprender a cada instante. Pero al tratar de desprendernos de él, se adhiere a nuestro cuerpo de una forma inquietante. Es ese cadáver que ya somos de antemano, desde que hemos nacido. Es la teología de la muerte. Todo lo teológico son restos muertos, despojos. Ese trozo de placenta que nos acompaña desde el nacimiento. «Introibo ad altare Dei», entonó Bluck Mulligan a modo de introito (Joyce, 1922: 3; 1976: I, 71). No, no entraré. Estoy ya dentro. Es el altar del mundo: «Gravemente se fue dando vuelta y bendiciendo tres veces la torre, los campos de alrededor y las montañas que se despertaban» (Joyce, 1922: 3; 1976: I, 71). ¿Qué veo mirando a lo lejos? El mar, la madre dulce gris, el mar verdemoco, el mar tensaescrotos, el mar, la mar, nuestra gran madre dulce. «Ven a mirar» (Joyce, 1922: 5; 1976: I, 74), le dijo Buck Mulligan a Stephen Dedalus. «Nuestra poderosa madre» (Joyce, 1922: 5; 1976: I, 74), le dijo de nuevo. Y luego... Y luego volviendo

\footnotetext{
Y vuelvo a rastrillar, a rascar, a dragar el fondo de la ma(d)r(e). Apenas oigo el ruido del agua desde la pequeña habitación.

La matriz dentada no retira más que lo que puede, algas, piedras. Trozos, bocados, puesto que aquélla muerde. Despegados. Pero el resto pasa entre sus dientes, entre sus labios. No se puede apresar la ma(d)r(e). Ella se vuelve siempre a formar.

Resta. Allí, igual, tranquila. Intacta, impasible, siempre virgen (Derrida, 1974: 229).
} 
El agua del mar, o cualquier otra cosa que significara -juego de palabras - un pedazo o un momento de mot (palabra), mo, por ejemplo, u ot, o mor, mors (bocado), mort (muerte, muerto), o nombre propio que afecta si no encenta a lo más cercano, acompañándolo sin cesar, pero como un extranjero... (Derrida, 1986: 90).

repentinamente sus grandes ojos inquisitivos desde el mar a la cara de Stephen: «La tía cree que mataste a tu madre [... ] Podías haberte arrodillado cuando te lo pidió tu madre agonizante... Te pidió con su ultimo aliento que te arrodillaras y rezaras por ella. Y te negaste. Tienes algo de siniestro» (Joyce, 1922: 5-6; 1976: I, 74). La mar, la madre, thalatta, thalatta, epo oinopa pontos, nosotros los hiperbóreos:

Ella se le había acercado en un sueño después de morir, con su cuerpo consumido, en la suelta mortaja parda, oliendo a cera y palo de rosa; su aliento, inclinado sobre él, mudo y lleno de reproche, tenía un leve olor a cenizas mojadas. A través de la bocamanga deshilachada veía a ese mar saludado como gran madre dulce por la bien alimentada voz de junto a él. El anillo de bahía y horizonte contenía una opaca masa verde de líquido. Junto al lecho de muerte de ella, un cuenco de porcelana blanca contenía la viscosa bilis verde que se había arrancado del podrido hígado en ataques de ruidosos vómitos gimientes (Joyce, 1922: 6; 1976: I, 74-75).

Obsesión de Stephen: «Ella tenía la puerta abierta, quería oír mi música» (Joyce, 1922, 10; 1976, I, 80). Escena de repetición: «En un sueño, silenciosamente, se le había acercado, con su cuerpo consumido, en la suelta mortaja parda, oliendo a cera y palo de rosa: su aliento, inclinado sobre él con mudas palabras secretas, tenía un leve olor a cenizas mojadas» (Joyce, 1922: 11; 1976: I, 80-81). Manía persecutoria: los restos de los que no puedo desprenderme. El fantasma que me mira de frente, el muerto, el reproche:

Sus ojos vidriosos, mirando fijamente desde más allá de la muerte, para agitar y doblegar mi alma. A mí solo. El cirio fantasmal sobre la cara torturada. Su ronca respiración ruidosa estertorando de horror, mientras todos rezaban de rodillas. Sus ojos puestos en mí para derribarme. Liliata rutilantium te confessorum turma circumdet: jubilantium te virginum chorus excipiat. ¡Vampiro! ¡Masticador de cadáveres! No, madre. Déjame ser y déjame vivir (Joyce, 1922: 6; 1976: I, 81).

Era el clamor del alma de Stephen - «Stephen, todavía temblando del clamor de su alma, oyó el cálido correr de la luz del sol y, en el aire detrás de él, palabras amigas» (Joyce, 1922: 11; 1976: I, 81)-, que más tarde, como un tañido fúnebre, oirá a través de los ecos del toque de las horas de las campanas de la iglesia de San Jorge. «Déjame ser y déjame vivir» (Joyce, 1922: 11; 1976: I, 81). Ser y vivir, ¿son acaso lo mismo? Vivir es ser sin duda, pero ser sin ser. ¿Acaso soy lo que he sido hace un instante? ¿No es eso vivir: ser a cada instante siempre otro? «Ahora soy otro y sin embargo el mismo» (Joyce, 1922: 12; 1976: I, 82). 
Luis Ferrero Carracedo

\section{Entre el cielo y la tierra}

Fijémonos en la escena. Ya de madrugada, Bloom llega a casa en compañía de Stephen. Éste toma una taza de cacao y, sin llave para entrar en su torre Martello, se dispone a marchar sin destino (Joyce, 1922: 679 ss.; 1976: II, 304 ss.). Es una escena de despedida. Antes de la ceremonia, como cuando uno se va a la piltra, la micción compartida («a orinar y a la cama», dice el dicho), la del judío y la del cristiano, la del viejo y la del joven, la del circuncidado y la del incircunciso. A primera vista todo resulta paradójico. El viejo Bloom, el judío, el circuncidado, sólo tiene preocupaciones terráqueas: el «invisible audible órgano colateral del otro», es decir, su pene, su pene circunciso, no le trae otros problemas que los de un pene con el glande destocado: la irritabilidad, la tumescencia, la rigidez, la reactividad, la dimensión, la higiene, la pelosidad; al joven Stephen, el cristiano, el incircunciso, no le acarrea problemas terráqueos sino celestiales, teológicos: la integridad sacerdotal de

La Epístola a los Gálatas asocia [...] el tema de la conversión (siempre una experiencia de la mirada interior vuelta hacia la luz en el momento de la revelación, es decir en el momento de la verdad) con el tema de la circuncisión. Éste se torna inútil después de la revelación o el "desvelamiento" de Cristo ("Porque en Cristo Jesús la circuncisión no sirve para nada y el prepucio tampoco, sino la fe que actúa por la caridad" $(5,6)$ (Derrida, 1990: 117).

Por ejemplo, y le pongo fecha, es la primera página de las agendas: "Circuncisión, nunca he hablado de otra cosa, considerad el discurso sobre el límite, los márgenes, las marcas, las marchas, etc., la clausura, el anillo (alianza y don), el sacrificio, la escritura del cuerpo, el phármakos excluido o suprimido, la cortadurta/costura de Glas, el golpe y el recosido, de ahí la hipótesis según la cual es de eso, de la circuncisión, de la que, sin saberlo, no hablando nunca o hablando de paso, como de un ejemplo, yo hablaba y me permitía hablar siempre, a menos que -otra hipótesis- la circuncisión misma no sea sino un ejemplo de eso de lo que yo hablaba, sí, pero yo he sido, yo soy y seré siempre, yo y no otro, circunciso..." (Derrida, 1991: 70-71).

Jesús circuncidado, la

hiperdulía simple o el cuarto grado de latría a la reliquia del divino prepucio concedido a la abscisión de tales excrecencias divinas como el pelo o las uñas de los pies (Joyce, 1922: 719; 1976: II, 352). ¿Paradoja en verdad? No olvidemos las palabras de Glas:

La circuncisión es un corte determinante. Permite cortar pero, a la vez, quedar pegado al corte. El judío se las arregla para que lo cortado quede pegado al corte. Errabundia judía limitada por la adherencia y el contra-corte. El judío sólo es cortante para tratar así, para contraer el corte consigo mismo: "(Abraham) siguió firmemente pegado a su separación que hizo visible por medio de una propiedad corporal que se impuso a sí mismo e impuso a sus descendientes" (Derrida, 1974: 51).

En el circunciso el prepucio se experimenta como adherencia, como resto. Lo que separa de la naturaleza establece una nueva naturaleza: la unión a la tierra, la familia endogámica (Joyce, 1922: 215; 1976: I, 342: «Los judíos -son palabras de Stephen, 
lector de Santo Tomás de Aquino- [...] son los más dados de todas las razas al matrimonio consanguíneo (intermarriage)»), el paraíso terráqueo... En el incircunciso la palabra se hace carne, para liberar al espíritu de la carne: mi reino no es de este mundo, pero se funda en piedra, necesita los restos:

Todo sucede en torno a un sepulcro. Sin duda el recuerdo del cuerpo putrefacto se ha borrado en un primer momento en la intuición de la gloria, pero ha vuelto, ha insistido, en la medida misma en que la escisión continuaba su trabajo. Mientras el cuerpo muerto reste ahí, en la interminable descomposición de las reliquias, el espíritu no se eleva nunca lo suficientemente alto, es retenido como una suerte de efluvio, de gas en fermentación encima del cadáver. Una especie de pesantez "tira de él hacia la tierra" (ihn zur Erde zieht) y "el Dios debe flotar (schweben) entre lo ilimitado, lo infinito del cielo y la tierra, esa reunión de limitaciones distintas, en medio de ambos". El espíritu es todavía como una suerte de águila que querría elevarse mientras el "plomo" (Blei) vuelve pesadas sus alas o sus patas. Jesús se asemeja ahora a Moisés. Es decididamente demasiado judío. [...] En su errabundia y en su enseñanza Cristo permanece clavado o pudriéndose: "ligazón monstruosa" (ungeheure Verbindung). (Derrida, 1974: 106)

Todo sucede entre el cielo y la tierra. Así también en la escena de despedida. La estrella fugaz que rasga el cielo como un río de esperma, la llave macho introducida en la cerradura hembra que posibilita una apertura de libre egreso y libre ingreso, la despedida en el umbral, donde se encuentran «las líneas de sus valedictorios brazos formando cualquier ángulo menor que la suma de dos ángulos rectos» (Joyce, 1922: 720; 1976: II, 353): todo ello acompañado por el sonido del toque de la hora de la noche por el son de las campanas de la iglesia de San Jorge. Bloom y Stephen oyen los ecos. Pero ¿qué oyen? ¿Qué ecos de sonido golpean sus oídos? ¿Acaso no oyen el toque de campana? Ecos celestes oye Stephen, ecos terrestres oye Bloom. Lo terrestre está en lo celeste y lo celeste en lo terrestre. O quizá todo está entre ambos, como abriéndose en dos direcciones, hendiéndose en dos costados, el allende y el aquende que cristalizan en el eco de un toque de campana. ¿Qué oye Stephen? «Liliata rutilantium. Turma circundet. Iubilantium te virginum. Chorus scipiat» (Joyce, 1922 : 720; 1976 : II, 353). Una plegaria de iglesia, una encomienda a Dios, ecos sueltos de una oración fúnebre. ¿Qué oye Bloom? Los armónicos siguiendo por el aire. Los cuartos, las horas: «Ay-oh, Ay-oh...» (Joyce, 1922: 71 y 720; 1976: I, 159 y II, 353). Entre el cielo y la tierra. De hecho, cuando se quedó solo, Bloom oyó «la doble reverberación de pies en retirada en la tierra sustentada por los cielos» (Joyce, 1922: 720; 1976: II, 354).

\section{Entre el padre y el hijo}

Stephen Dedalus, el joven Kinch sombra de Kinch el viejo, Jafet en busca del padre («Este demuestra por álgebra -dice Buck Mulligan refiriéndose a Stephen Dedalus a propósito de una pregunta de Heines sobre Hamlet- que el nieto de Hamlet es 
el abuelo de Shakespeare y que él mismo es el espectro de su padre» (Joyce, 1922: 19; 1976: I, 91), no puede desprenderse de los restos: «En el claro instante de silencio, Stephen vio su propia imagen en barato luto polvoriento entre las alegres vestimentas de los otros» (Joyce, 1922: 20; 1976: I, 91). Cuestión de espectros («¿Qué es un espectro?» (Joyce, 1922: 198; 1976: I, 328), se preguntará más tarde el propio Stephen ${ }^{3}$ ). No es una cuestión meramente literaria, es también y sobre todo una cuestión teológica. Joyce la pone en boca de Heines, el pelmazo inglés que se interesa por Hamlet: «He leído no sé donde una interpretación teológica -dijo meditabundo-. La idea del Padre y el Hijo. El Hijo esforzándose por reconciliarse con el Padre» (Joyce, 1922: 20; 1976: I, 92). El tema será recurrente, casi obsesivo. Aquí el lenguaje es paródico, la escena es burlesca, Buck Mulligan salmodiando la balada del jovial Jesús (Joyce, 1922: 20; 1976: I, 92: «Mi madre era judía y mi padre era un pájaro. / Con José el ebanista no puedo andar de acuerdo»). Parece una blasfemia, incluso desde la incredulidad: es el resto indesprendible. ¿Blasfemia o herejía? En la memoria de Stephen resonaba «el triunfo de las campanas broncíneas: et unam sanctam catholicam et apostolicam ecclesiam. [...] Símbolo de los Apóstoles en la misa del Papa Marcelo» (Joyce, 1922: 22; 1976: I, 9495). Algo más que una consigna, que un santo y seña. Una marcha más bien, una marcha triunfal:

Y detrás de su cántico el ángel vigilante de la Iglesia militante desarmaba y amenazaba a sus heresiarcas. Una horda de herejías huyendo con mitras de medio lado: Focio y todo el linaje de burlones de los que Mulligan era uno más, Arrio, guerreando toda su vida contra la consustancialidad del Hijo con el Padre, Valentín, despreciando el cuerpo terrenal de Cristo, Sabelio, que sostenía que el Padre era él mismo su propio Hijo (Joyce, 1922: 22; 1976: I, 94-95).

¿Qué hay detrás de todo esto a fin de cuentas? La cuestión del padre, la cuestión de la relación de padre-hijo. Derrida leyendo, interpretando, deconstruyendo a Hegel («La genealogía no puede comenzar por el padre» (Derrida, 1974: 12), es la cita inaugural de un largo y continuado discurso sobre el padre en la columna de Hegel; «Hipótesis diosdevenida padre en sí por no estar allí» (Derrida, 1974: 290), es la cita final donde aparece el padre en la columna de Genet ${ }^{4}$ ). Ecos derrideanos: Joyce leyendo, interpretando, deconstruyendo a Shakespeare. No se trata de la muerte del padre, sino más bien del hijo, de su muerte simbólica: la paternidad como mal necesario, como ficción legal, como destrucción de belleza (Joyce, 1922: 217-218; 1976: I, 344-345). Volvamos con Joyce -en una vuelta como trampolín para reencontrarnos con el espectro

\footnotetext{
${ }^{3}$ En este pasaje, J. M. ${ }^{a}$ Valverde traduce ghost por fantasma y no por espectro, como hace en otras ocasiones. Modificamos su traducción para mantener siempre la misma versión. No se ha de olvidar que el tema de los espectros y de los fantasmas abunda en la obra de Derrida.

${ }^{4}$ La cuestión del padre, y más concretamente la de la relación padre-hijo ocupa en lugar central en Glas. Indiquemos solamente que en el término padre aparece 237 veces en la columna de Hegel y 43 en la columna de Genet.
} 
del padre del Hamlet- a Sabelio el Africano, recogiendo las palabras de Stephen en respuesta a su propia pregunta: «¿Soy yo padre? ¿Y si lo fuera?»:

Sabelio el Africano, el más sutil heresiarca de todas las bestias del campo, sostenía que el Padre era Él Mismo Su Propio Hijo. El mastín Aquino, para quien ninguna palabra ha de ser imposible le refuta. Bueno: si el padre que no tiene un hijo no es un padre, ¿puede ser hijo el hijo que no tiene padre? Cuando Rutlandbaconsouthamptonshakespeare u otro poeta del mismo nombre en la comedia de los errores escribió Hamlet, no era meramente el padre de su propio hijo sino que, no siendo ya hijo, era y se sentía ser el padre de toda raza, el padre de su propio abuelo, el padre de su nieto por nacer, quien, según el mismo criterio, nunca nació, pues la naturaleza, según la entiende el señor Magee, aborrece la perfección (Joyce, 1922: 218; 1976: I, 345).

Es el Hamlet de Shakespeare como un «cuento de espectros» (Joyce, 1922: 198; 1976: 318) frecuentado, en boca de Stephen, por la misma cuestión teológica:

Es un espectro, una sombra ahora. El viento junto a las rocas del Elsinore o lo que os parezca bien, la voz del mar, una voz oída sólo en el corazón de aquél que es la sustancia de su sombra, el hijo consustancial con el padre (Joyce, 1922: 208; 1976: I, 330-331).

Relación padre-hijo: compleja relación a la postre indecidible y cuya representación exige la técnica ignaciana de la «composición de lugar» (Joyce, 1922: 199; 1976: I, 319): el actor Shakespeare, «espectro por ausencia», que «ha estudiado Hamlet todos los años de su vida», vestido con las ropas del sepultado rey de Dinamarca, «espectro por muerte», le habla al «hijo de su alma», al príncipe, al joven Hamlet, y al «hijo de su cuerpo», a Hamlet Shakespeare, muerto en Stratford (Joyce, 1922: 199; 1976: I, 319-320).

El espectro del padre, la relación padre-hijo, cuestión recurrente como la muerte de la madre: «Siguió andando por el sendero curvado en la subida. Liliata rutilantium./ Turma circundet./ Iubilantium te virginum» (I, 97). A fin de cuentas el amor matris -genitivo subjetivo y objetivo, el amor de la madre y a la madre, de esa madre y a esa madre que, como recordaba el joven Sargent cuando, al terminar la clase, Stephen le ayudaba a hacer los ejercicios de su cuaderno, «con su débil sangre y su leche agria de suero lo había alimentado y había escondido a la vista de los demás sus pañales» (Joyce, 1922: 30; 1976: I, 105)— «quizá sea la única cosa verdadera de la vida» (Joyce, 1922: 217; I, 1976: 344) $)^{5}$.

\footnotetext{
${ }^{5}$ De la importancia de la figura de la madre, desde un punto de vista "autobiográfico", Derrida ha dejado un impresionante testimonio en Circonfession, que merecería algo más, mucho más, que una nota a pie de página. Por lo que atañe a nuestro asunto, Christine von Heemen-Saff ha destacado un fuerte paralelismo entre Joyce y Derrida, a propósito de un pasaje del Ulises sobre la maternidad: «Al igual que Stephen Dedalus en Ulises, cuyas teorías acerca del arte dependen de la huida de la muerte, de la materialidad y de la madre hacia una "postcreación", Derrida imagina y proyecta un mundo postmaterial en el que la filiación ha pasado a través de la palabra: «En vientre de mujer la palabra se hace carne, pero en el espíritu del hacedor toda carne que pasa se hace la palabra que no pasará. Esa es la postcreación» (Joyce,
} 


\section{Entreser}

De nuevo restos: «El zorro enterrando a su abuela bajo una mata de acebo» (Joyce, 1922: 28; 1976: I, 103). Y de nuevo el tañido fúnebre: «Las campanas del cielo / están tocando a duelo» (Joyce, 1922: 28; 1976: I, 103). Y poco después, al observar al término de la clase la «leve mancha de tinta en forma de dátil, reciente y húmeda como una huella de caracol» en al mejilla de Sargent, un alumno cuyo pelo enredado y cuyo cuello descarnado «daban testimonio de impreparación», Stephen sigue pensando en los restos, una vez más de la madre:

Feo e inútil, cuello flaco y pelo enredado y una mancha de tinta, una huella de caracol. Sin embargo, una le había amado, le había llevado en brazos y en el corazón. De no ser por ella la carrera del mundo le habría aplastado pisoteándolo, estrujado caracol sin hueso. Ella había amado esa débil sangre aguada sacada de la suya. ¿Era eso entonces real? ¿La única cosa verdadera en la vida? Sobre el postrado cuerpo de su madre cabalgó el fogoso Columbano con sagrado celo. Ella ya no existía: el tembloroso esqueleto de una ramita quemada en el hogar, un olor de palo de rosa y cenizas mojadas. Ella le había salvado de ser aplastado y pisoteado, y se había ido, escasamente habiendo sido. Una pobre alma ida al cielo: y en brezal, bajo el parpadeo de las estrellas, un zorro, el rojo hedor de rapìna en la piel, escuchaba, escarbaba la tierra, escuchaba, escarbaba y escarbaba (Joyce, 1922: 29; 1976: I, 104).

¿Qué escuchaba? ¿La voz del espectro? ¿La voz del espectro de la madre que ya no existía, que se había ido, escasamente habiendo sido? El espectro es ese ser escaso, que nunca deja de ser, que es no siendo, que entre-es, pues ni es ni no es; pero que no deja de reaparecer en cada instante, alimentado la vida y destruyéndola: vivimos de los restos que nos destruyen y nos crean (Joyce, 1922: 51; 1976: I, 131: «Oomb, allwombing tomb / Entre. Omnienventrador antro»-¿Por qué no la entrañada entraña?-). Escarbamos como el zorro. ¿No estarán vivos? ¿Acaso no están en la memoria? ¿Por qué, si no, el tañido fúnebre?

\section{Bibliografía}

Bennington, G. (1991) : Derridabase, en Bennington, G., y Derrida, J., Jacques Derrida. París, Seuil.

CAPUto, J. D. (1997): Deconstruction in a Nutshell: A Conversation with Jacques Derrida. Nueva York, Fordham University Press.

1922: 409; 1976: II, 32 ). Las palabras de Stephen anticipan el programa de Derrida. Quizás las meditaciones de Stephen sobre el ombligo como el signo de deuda del espíritu para con la madre naturaleza son también relevantes aquí. Lo que Stephen sueña y Derrida proyecta es el concepto de un vientre sin mancha, un sujeto sin ombligo saltando de las páginas de un libro como si lo hiciera del vientre de una madre» (Heemn-Saff, 2004: 178). Asimismo subraya la autora la escisión, el corte sin corte, que Derrida introduce en Circonfession entre la maternidad y la paternidad: por un lado, la madre carnal, judía, moribunda, y por otro, San Agustín, el Padre de la iglesia cristiana, como la imago paterna, trasunto de la paternidad espiritual de la palabra (véase Heemn-Saff, 2004: 179-183). 
DERridA, J. (1962): «Introduction», en HuSSERL, E., L’origine de la géométrie. Trad. Jacques Derrida. París, P. U. F.

- (1974): Glas. París, Galilée.

(1984): «Two words for Joyce», en AtTridge, D., y Ferrer, D., eds., Essays from the French. Cambridge, Cambridge University Press.

— (1985): «Deux mots pour Joyce», L'Herne, 50

(1986): Parages. París, Galilée.

(1987): Ulysse gramophone. Deux mots pour Joyce. París, Galilée.

(1990): Mémoires d'aveugle: l'autoportrait et autres ruines. París, Museo del Louvre.

(1991): Circonfession, en Bennington, G., y DeRrIDA, J., Jacques Derrida. París, Seuil.

- (1992): Acts of Literature. Ed. Derek Attridge. Nueva York, Routledge.

HeEmen-SAFF, C. von (2004): Joyce, Derrida, Lacan and the Trauma of History. Cambridge, Cambridge University Press

JoYCE, J (1922): Ulysses. University Park, Pennsylvania State University Press, 2007

(Trad. cast. de J. M. ${ }^{a}$ Valverde, 2 vols., Barcelona, Lumen, 1976).

LAWLORD, L. (1995): «The relation as the Fundamental Issue in Derrida», en McKenna, W. R., y Evans, J. C., eds., Derrida and Phenomenology. Doordrecht, Kluwer Academic Publishers.

- (2002): Derrida and Husserl: The Basic Problem of Phenomenology. Bloomington, Indiana University Press

PeretTI, C. de (1989): Jacques Derrida: texto y deconstrucción. Barcelona, Anthropos. Roughley, A. (1999), Reading Derrida Reading Joyce. Gainesville, University Press of Florida. 